\title{
E1 racismo cotidiano en la universidad colombiana desde la experiencia vivida por los estudiantes negros en Bogotá ${ }^{1}$
}

\author{
Oscar A. Quintero Ramirez ${ }^{2}$ \\ Universidad del Rosario, Bogotá, Colombia ${ }^{3}$ \\ oquinteror@yahoo.com \\ Recibido: 22 de julio de 2013 \\ Aceptado: 9 de septiembre de 2013
}

1 El presente artículo presenta algunos de los principales resultados de la investigación doctoral titulada "Racisme et Discrimination à l'université. Lectures croisées des sociétés Française et Colombienne à partir de l'expérience vécue des étudiants noirs à Paris et Bogota”. Université Rennes 2, 2013. La tesis presenta los resultados de la investigación comparativa entre Francia y Colombia. Debido a los limites en cuanto extensión de la presente publicación así como a la pertinencia social de la misma, solo presentamos los hallazgos para el caso colombiano. El texto está disponible en línea y en español en la siguiente dirección: http://tel.archives-ouvertes.fr/ tel-00807356

2 Sociólogo, Magíster en Geografia Social y Doctor en Sociología.

3 Profesor Principal de la Escuela de Ciencias Humanas. 


\title{
El racismo cotidiano en la universidad colombiana desde la experiencia vivida por los estudiantes negros en Bogotá
}

\section{Resumen}

El presente artículo expone los resultados de una investigación sociológica sobre las discriminaciones raciales en las universidades colombianas. Se entiende el racismo como un proceso social, y con base en un trabajo empirico de tipo cualitativo a partir de entrevistas en profundidad, el artículo se aproxima al racismo cotidiano vivido por jóvenes que estudian en las universidades bogotanas y que son racializados como negros o negras de acuerdo con las construcciones de la alteridad racial en Colombia. Los principales mecanismos de manifestación del racismo y de las discriminaciones identificados en la investigación, se expresan de manera sutil o a partir de eufemismos y tienden a generar y reproducir una supuesta inferioridad y subordinación de los estudiantes negros en las universidades de Bogotá, de manera paradójica frente a los valores y principios de universalidad y meritocracia que se encuentran en los orígenes mismos del ethos universitario en el país.

Palabras Clave: Discriminación racial, Racismo cotidiano, Educación superior, Universidades, Estudiantes afrocolombianos.

Palabras clave descriptores: Discriminación racial, Discriminación en la educación superior, Relaciones raciales, Afrocolombianos, Estudiantes universitarios afroamericanos

\section{Everyday Racism in Colombian Universities: The Experience of Black Students in Bogotá}

\begin{abstract}
This paper presents the results of a sociological research on racial discrimination in Colombian universities. Racism is understood as a social process and based on an empirical qualitative work from in-depth interviews, the article approaches the everyday racism experienced by students in universities in Bogotá who are racialized as black men or black women according to the constructions of racial otherness in Colombia. The main mechanisms of manifestation of racism and discrimination identified in the research are expressed subtly or from euphemisms and they tend to generate and reproduce a supposed inferiority and subordination of black students at universities in Bogotá, paradoxically to the core values and principles of universality and meritocracy present in the very origins of university ethos in the country.
\end{abstract}

Keywords: Racial Discrimination, Everyday Racism, Higher Education, Universities, Afro-Colombian Students.

Key words plus: Race Discrimination, Discrimination In Higher Education, Race Relations, AfroColombian, African American College Students

\section{O racismo cotidiano na universidade colombiana desde a experiência vivida pelos estudantes negros em Bogotá}

\begin{abstract}
Resumo
O presente artigo expõe resultados de pesquisa sociológica sobre os preconceitos raciais nas universidades colombianas. Entende-se o racismo como processo social e, baseado em trabalho empírico de tipo qualitativo a partir de entrevistas em profundidade, o artigo se aproxima do racismo cotidiano vivido pelos jovens que estudam nas universidades bogotanas e que são racializados como negros ou negras de acordo com as construções da alteridade racial na Colômbia. Os principais mecanismos de manifestação do racismo e as discriminações, identificados na pesquisa são exprimidas de maneira sutil ou a partir de eufemismos e tendem a gerar e reproduzir uma suposta inferioridade e subordinação dos estudantes negros nas universidades de Bogotá, de maneira paradoxal frente aos valores e princípios de universalidade e meritocracia encontrados nas origens próprias do ethos universitário no país.
\end{abstract}

Palavras-Chave: Discriminação racial, Racismo cotidiano, Ensino superior, Universidades, Estudantes afrocolombianos.

Palavras-chave descritores: Discriminação racial, Discriminação no ensino superior, Relações raciais, Afro, Estudantes universitários americanos africanos 


\section{Introducción}

En Colombia surgió recientemente un campo de investigación sobre el racismo y las discriminaciones que se ha visto plasmado en un naciente auge en la producción académica y editorial. Principalmente desde el año 2000 se comenzaron a publicar estudios relacionados con las discriminaciones étnico-raciales y sus configuraciones de género en sectores urbanos populares (Langebaek y Leal, 2007; Viveros, 2007; Arocha, Guevara, Londoño, Moreno y Rincón, 2007; Mosquera, 2007; Viáfara y Urrea, 2006). De igual manera, los estudios actuales se han preocupado por los vínculos entre raza y clase social (Meertens, 2008; Meertens, Viveros y Arango, 2006; Urrea, 2011; Gil, 2010), asimismo hay un número creciente de investigaciones sobre el racismo a partir de la lingüística y el análisis del discurso (Fonseca, 2009). Sin embargo, dentro de este nuevo campo de investigación, los estudios sobre el racismo y las discriminaciones en la educación superior son, por ahora, bastante escasos y obedecen a trabajos exploratorios (Meza, 2008; Palacios, 2005).

El campo social de la educación superior y específicamente la universidad como su referente espacial y simbólico más importante, ha sido uno de los sectores que menos atención ha recibido por parte de la investigación en ciencias sociales. Esto se debe en parte a la preeminencia de los análisis sociológicos sobre la educación a partir de la perspectiva de las desigualdades sociales, las cuales se entienden comúnmente como desigualdades socioeconómicas y por ende, desde la clase social como categoria de análisis principal (Gaviria, 2002). A pesar de la predominancia de un contexto oficial multicultural, la universidad colombiana se sigue guiando por los preceptos de meritocracia establecidos en la época republicana. Esto ha impedido cuestionar la existencia de discriminaciones de tipo racial en esta institución universalista e igualitaria en sus principios ideológicos y también ha suprimido la puesta en práctica efectiva de algunas de las medidas de acción afirmativa planteadas desde la Constitución de 1991 (Caicedo y Castillo, 2008).

De acuerdo con lo anterior, en las ciencias sociales colombianas se evidencian vacíos importantes en términos de saber cómo se manifiestan las discriminaciones y el racismo en la educación superior y cómo influyen en la re-producción de las desigualdades educativas y sociales que afectan a las distintas minorias racializadas en el país. Este escrito pretende dar herramientas para llenar algunos de los vacíos de conocimiento sobre las manifestaciones del racismo en las universidades colombianas y de evidenciar la forma en que se viven 
y asimilan las experiencias discriminatorias por parte de los estudiantes, hombres y mujeres, que son racializados en el contexto colombiano bajo la denominación de negros o afrocolombianos ${ }^{4}$.

Para tal propósito, la primera parte del artículo retoma algunos elementos teóricos y conceptuales en relación con categorías como raza, racismo y discriminación. Luego se exponen algunos aspectos metodológicos fundamentados en la experiencia investigativa sobre la cual se basa el presente escrito. Finalmente se presentan los principales hallazgos de la investigación en relación con la problemática del racismo cotidiano vivido por estudiantes negros y negras en Bogotá.

\section{Sobre las nociones aún controvertibles de raza, racismo y discriminación}

La definición de las colectividades humanas en términos de grupos étnicos o grupos raciales ha sido un tema de profundas discusiones que no ha generado necesariamente una unanimidad dentro de las ciencias sociales, especialmente en disciplinas como la sociología (Poutignat y Streiff-Fénart, 1995). A pesar de que en un principio estos dos términos se encuentran estrechamente ligados, también es clara la diferenciación que asocia el primero con la cultura y el segundo con la naturaleza.

Si bien se podría hablar de fenómenos de racismo en épocas anteriores a la modernidad, la idea moderna de la raza aparece a partir del siglo XVIII con el denominado racismo científico que planteaba la existencia de diferencias esenciales y naturales entre los grupos humanos y que de esta forma, generó jerarquías sociales a partir de particularidades fenotípicas consideradas como diferencias biológicamente esenciales. La producción de estas teorías estuvo acompañada de explicaciones científicas sobre la inferioridad de unas razas frente a otras y la legitimidad de la dominación de aquellas que se suponían inferiores por parte de las superiores (Agudelo, 2002).

La socióloga francesa Colette Guillaumin (1992/2010) plantea algunas aclaraciones de tipo conceptual rastreando el origen y las distintas acepciones de los términos de raza y etnia. En ese sentido,

4 El uso de las palabras negro y negra en cursiva remite al carácter ideológico, histórico y socialmente construido de las categorizaciones raciales y de la idea de raza como una forma de generardistinciones entre los seres humanos a partir de diferenciaciones biológicas supuestas o reales. 
Guillaumin recuerda que el adjetivo étnico era un equivalente de racial en sus orígenes a mediados del siglo XVIII. Con el tiempo, la etnia fue remplazando a la raza, pero el sentido del segundo término se ha deslizado y mantenido en el primero, utilizándose frecuentemente como eufemismos intercambiables. Más allá de los términos empleados, la autora se interesa en identificar las características de la definición ideológica de los grupos humanos como provistos de una esencia propia que es "productora de conductas y de cualidades específicas inscritas en la carne y la sangre, en fin lo mismo que a lo largo del siglo XIX y hasta el nuestro, responde a la noción de raza" (Guillaumin, $1992 / 2010$, p. 37). En suma, la idea de raza es el resultado de un proceso histórico e ideológico y no un suceso sin memoria, como justamente lo presenta la ideología racista con el fin de naturalizar la dominación.

En la actualidad pareciera que hay un común acuerdo en la no aceptación de la raza como una categoría científica fundamentada en cualquier diferencia biológica sino como una construcción social, histórica e ideológicamente definida. Así, para muchos sociólogos es imperativo el uso de la palabra entre comillas o en letra cursiva, con el fin de posicionarse frente a las doctrinas racistas y racialistas de otrora. Por otro lado, aunque la categorización racial está frecuentemente asociada a determinadas diferencias fenotípicas que históricamente se han construido como tales, el interés sociológico en el estudio de la raza es el de estudiar las causas y consecuencias de la división socialmente construida de los grupos sociales con base en esas categorias así llamadas raciales, o mejor, con base en la idea de raza imperante en contextos sociales y momentos históricos específicos.

En segundo término, ha surgido la idea de que por ser una construcción social, la raza carecería entonces de utilidad analítica, prefiriendo el uso de conceptos como etnicidad y clase social. Al respecto, estamos de acuerdo con algunos autores que piensan que quitarle el papel analítico a la raza puede ser una posición que niega el impacto autónomo que esta pueda tener en la vida social (Wade, 1997).

Dicho en otros términos, la raza, al igual que otras categorías construidas socialmente (v.gr. clase o género), tiene una realidad social; esto quiere decir que luego de que estas categorias son creadas, se producen efectos reales en los actores y grupos sociales así racializados en términos de negros, blancos, árabes, etc. (Bonilla-Silva, 2006, pp. 8-9). En ese sentido, la noción de raza no sólo es útil sino necesaria, en la medida en que emplear otros términos, muchos de ellos eufemísticos, 
puede ocultar los significados de los que dependen las significaciones raciales (Wade, 1997, p. 18) y sus consecuencias sociales reales en la jerarquización y los procesos de dominación social.

Por último, si bien la noción de raza está fuertemente relacionada con aquella de racismo, creemos pertinente hacer una distinción analítica entre las dos. Aunque están estrechamente relacionadas, el racismo nos remite a configuraciones específicas de dominación social, fundamentadas en la idea de la raza, de acuerdo con determinados contextos sociales, históricos, ideológicos, culturales y geográficos. Dicho de otra forma, los racismos deben ser ubicados en sus contextos espaciales y temporales (Wade, 1997, p. 398).

Como lo recuerdan varios autores (De Rudder, Poiret y Vourc'h, 2000, pp. 40-45; Bonilla-Silva, 2011; Essed, 1991), la distinción entre racismo individual y racismo institucional surgió de los militantes de los Derechos Civiles en los Estados Unidos en la década de1960. Frente a la persistencia de las desigualdades y las estratificaciones raciales en este país, los militantes pusieron especial énfasis en la comprensión de la desigualdad estructural que afectaba a la población negra no solo desde los prejuicios, las intenciones y los comportamientos discriminantes de la mayoria blanca (que era explícitamente racista), sino desde un conjunto integrado de dispositivos que aseguraban la perpetuación del poder de los blancos desfavoreciendo sistemáticamente a los negros (Bonilla-Silva, 2011).

No obstante, esta concepción del racismo institucional ha sido objeto de varias críticas, de las cuales mencionaremos las más importantes. En primera instancia, desde un punto de vista teórico, se limita a plantear una posición reivindicativa a partir de la cual todo puede interpretarse como racista. Por otro lado, lo institucional puede ser sociológicamente polisémico y algunas veces contradictorio. Así, para algunos investigadores los términos institución e institucional identifican relaciones estructurales dentro de un aparato regido por diferentes funciones, sin tener en cuenta necesariamente el papel de la ideología en la estructuración del racismo en la sociedad (Essed, 1991, p. 37). Para otros investigadores el racismo institucional sí tiene en cuenta el factor ideológico del mismo, pero estos terminan por limitar la comprensión del racismo a ese nivel ideológico; esto quiere decir que no da herramientas para entender cómo es que esa ideología llegó a institucionalizarse (Bonilla-Silva, 2006).

Por contraste, el racismo individual estaría entonces conformado por los actos racistas cometidos abiertamente por individuos. Se trata 
de su expresión directa en donde la hostilidad es reivindicada o la discriminación es abierta. Algunos de los trabajos desarrollados bajo esta perspectiva consisten en examinar las actitudes de los individuos para determinar los niveles de racismo en la sociedad. Esta perspectiva tiene varias limitantes a la hora de dar una mejor comprensión del fenómeno del racismo. En primer lugar, como lo recuerda Essed (1991), el término individual es una contradicción en sí misma pues el racismo es, por definición, la expresión o la activación de un poder grupal. Asimismo, considerar que el racismo emerge de casos aislados de individuos racistas y no de la sociedad como un sistema, tiene algunas consecuencias analiticas: las instituciones sociales no podrian ser racistas y estudiar el racismo se reduciria a identificar individuos prejuiciados o malos, en relación con los buenos (Bonilla-Silva, 2011).

Como una forma de superar esta distinción entre racismos individuales e institucionales que presenta limites heurísticos para la presente investigación, algunos autores han propuesto la noción de racismo cotidiano (Essed, 1991). Este significa entonces el entrelazamiento del racismo en la fábrica del sistema social (Essed, 1991, p. 37), un concepto que además propende por la superación de la dicotomía entre racismos individuales e institucionales y se enmarca dentro de la concepción del racismo entendido como un proceso social. El propósito de esta perspectiva ha sido el de tener en cuenta el impacto imperativo que ejercen las ideas y prácticas arraigadas en la actividad humana, como también reconocer que el sistema social se reconstruye continuamente en la vida cotidiana y que, bajo ciertas condiciones, los individuos se resisten a las presiones para que se conformen a las necesidades del sistema (Essed, 1990; 1991).

En ese sentido, su propuesta pretende ir más allá de las perspectivas macro-sociológicas en las cuales las instituciones y estructuras sociales son independientes de las prácticas en la vida diaria; como algo que está por encima del nivel mundano de la práctica y la experiencia (Essed, 1991, p. 38). Se trata entonces de poner en evidencia la mutua interdependencia de las dimensiones micro y macro del racismo. Así,

(...) desde un punto de vista macro, el racismo es un sistema de desigualdades estructurales y un proceso histórico, ambos creados y recreados a través de prácticas rutinarias (...). Desde un punto de vista micro, determinadas prácticas pueden ser evaluadas en términos de racismo, solo cuando son consistentes con [nuestro conocimiento 
de] las macro estructuras de la desigualdad racial, sean sus consecuencias intencionales o involuntarias. (Essed, 1991, p. 39)

Por último, cuando se habla de discriminación nos ubicamos más en el nivel de los actos y los hechos, de la práctica social y de su interpretación por los actores sociales mismos, que en el nivel de las opiniones, de las representaciones y de los estereotipos (De Rudder, Poiret y Vourc'h, 2000, p. 43). No sobra recordar que las discriminaciones han sido abordadas clásicamente desde dos perspectivas: como prácticas explícitas y como un resultado de dinámicas sociales.

La primera se centraría en el análisis de prácticas intencionales, actos explícitos en contra de determinados grupos o personas los cuales tienen como función el mantener y reforzar sin ningún miramiento, su subordinación. La segunda perspectiva adoptaría el asunto de las discriminaciones como un resultado de dinámicas sociales. Por lo general este tipo de abordaje tiene en cuenta aproximaciones estadísticas para mirar el mayor o menor grado de acceso o igualdad que tienen las personas o grupos en relación con un bien o un servicio específico.

Una tercera perspectiva de comprensión de las discriminaciones está más relacionada con la noción del racismo cotidiano propuesta anteriormente. A partir de esta, las discriminaciones se entienden en términos de proceso social en el cual se enmarcan las relaciones sociales representativas de los sistemas de dominación y por medio del cual estos sistemas se refuerzan. Al entender las discriminaciones bajo esta perspectiva podremos abordar la articulación de los aspectos micro y macro en el análisis. De acuerdo con esto, en la presente investigación entenderemos la discriminación como:

La aplicación de un tratamiento a la vez diferente y desigual hacia un grupo, y por ende a los individuos que lo componen, en función de rasgos socialmente construidos como diferencias negativas, en relación con un actor dominante (Poiret y Vourc'h, 1998, p. 16)

y dentro de un campo social específico, añadiríamos.

Esto quiere decir que, ya sea de manera consciente o inconsciente, intencional o sin intención, la jerarquización socio-racial es mantenida y reforzada por medio de las instituciones legales, culturales, religiosas, educativas, económicas, políticas, medioambientales, etc., 
en una sociedad específica. Una de las características de esta discriminación es su carácter acumulativo en las personas y los grupos racializados en donde los criterios discretos y rutinarios, así como los hábitos comunes que forman el juicio y la evaluación, pueden tener un efecto más desfavorable en los grupos minoritarios en la medida en que estos últimos no poseen una forma legitima de cuestionarlos en su principio (De Rudder, Poiret y Vourc'h, 2000, p. 44).

Luego de estas aclaraciones teóricas y nuestra ubicación en la corriente de estudios sobre el racismo cotidiano y desde una perspectiva de las discriminaciones como proceso social, presentaremos a continuación los principales aspectos metodológicos que caracterizaron la investigación empírica sobre la cual se fundamenta el presente artículo.

\section{Escogencias metodológicas, terreno, técnicas de recolección y análisis de la información ${ }^{5}$}

Un primer problema metodológico al cual nos confrontamos para poder responder a la problemática de investigación tuvo que ver con el tipo de instituciones sobre las cuales debía realizarse el trabajo de campo. En ese sentido se priorizó el tipo de instituciones que ofrecieran una formación profesional, esto es que no tuvieran la prioridad en la formación de tipo técnica y tecnológica. La universidad se perfilaba entonces como el principal escenario para desarrollar el trabajo de campo, teniendo en cuenta por supuesto las diferencias inherentes que presentan este tipo de instituciones en Bogotá.

De acuerdo con esto y a pesar de que el interés de la investigación partía de una problemática de investigación (el racismo y las discriminaciones en la universidad) y no a partir del estudio de grupos raciales o grupos identitarios previamente seleccionados, fue necesario limitar la problemática, o mejor dicho redefinirla a partir del estudio de esas discriminaciones vistas desde la perspectiva de los grupos que han sido minorizados socialmente a partir de la idea de raza en Colombia.

Esto último nos condujo entonces a la siguiente pregunta: ¿qué tipo de grupo minorizado racialmente podría colaborarnos con el estudio y por qué? Al hacer entonces un balance sobre los distintos grupos racializados en Colombia, susceptibles de ser el grupo de referencia

5 Para una presentación más detallada de la metodología global de la investigación, véase Quintero (2013). 
para la investigación, encontramos un panorama amplio y muy interesante. Insistimos en la expresión de grupo de referencia pues no se trata de un estudio sobre los negros o los indigenas sino de una perspectiva de análisis del racismo y las discriminaciones a partir de la experiencia de unas personas que han sido construidas social e históricamente como minorías raciales y que en su diario vivir puede que sean interpelados o no como tales por los demás.

En ese sentido se privilegió el trabajo con un solo grupo de referencia: las personas negras o afrocolombianas. Como una explosión de la mirada multiculturalista de la sociedad, el asunto de las categorias tampoco era tan fácil como parecía. A pesar de que públicamente es considerado legítimo y hasta políticamente correcto, hablar y mencionar a las minorias étnico-raciales, no se puede decir que hay unanimidad en la forma de nombrarlas, esto es especialmente cierto para el caso de la gente negra. La solución metodológica consistió en dejar abierto el espectro a las personas que se consideraran a sí mismas como negras o como afrocolombianas. Esta última categoria es mucho más reciente y ha sido movilizada principalmente por sectores asociativos y de la élite intelectual en Colombia, sin embargo en la cotidianidad tampoco se usa como tal y se ha reducido a la expresión afros funcionando como un sinónimo de la categoria negros.

Una vez definidos estos aspectos, ¿cuál era entonces la técnica que mejor se adecuaba a esta problemática de investigación?, ¿cómo abordar mejor la experiencia de discriminación y racismo vivida por los estudiantes negros en Bogotá?

En su estudio pionero sobre el racismo cotidiano vivido por mujeres negras de Estados Unidos y los Países Bajos, Philomena Essed (1991) propone algunos elementos metodológicos de interés y establece dos razones por las cuales se privilegia el estudio del racismo cotidiano a partir del relato de las experiencias vividas por diferentes personas. La primera razón tiene que ver con las características de este tipo de discriminación: el racismo cotidiano es un fenómeno multidimensional y se reproduce a través de múltiples relaciones y situaciones. En ese sentido, la noción de experiencia se entiende de una forma multidimensional, que puede incluir eventos específicos (micro) o que también puede estar relacionada con el conocimiento de fenómenos generales en las propias definiciones de la realidad (estructural). La segunda razón para estudiar experiencias de racismo desde las experiencias de las personas negras es que muchas veces el racismo se expresa en formas encubiertas o sutiles lo cual hace 
que desde la perspectiva del grupo dominante, se tienda a negar o mitigar los efectos racializantes de determinadas situaciones (Essed, 1991, pp. 57-58).

Una tercera razón, añadiríamos, tiene que ver con el carácter situado del conocimiento. Esto quiere decir que los mejores 'sociólogos' son aquellas personas que viven las problemáticas sociales pues solo ellas ocupan la posición social y viven la condición social que las lleva a ser discriminadas. En este caso los mejores sociólogos son los estudiantes entrevistados, aquellas mujeres y aquellos hombres que en Colombia han vivido en carne propia la experiencia de racialización.

Así pues, Essed (1990; 1991) concluye que la mejor técnica de investigación en este caso puede ser las entrevistas no directivas o entrevistas en profundidad en la medida en que permiten acceder a relatos sobre el racismo. En ese sentido, no sobra recalcar que el corpus central de la información y de los resultados aquí presentados obedece a un trabajo riguroso y preciso de entrevistas en profundidad con estudiantes universitarios en Bogotá, hombres y mujeres que se consideran a sí mismos como negros, negras o afrocolombianos, afrocolombianas. Aunque el corpus central de la información se basó en esta técnica de investigación, también se hizo un trabajo complementario de aproximación etnográfica que nos sirvió para conocer distintas universidades, hacer los contactos para las entrevistas y observar la cotidianidad en las universidades en donde pudimos identificar pistas de investigación que luego fueron profundizadas en las entrevistas.

El principal método de búsqueda, contacto y concertación de entrevistas se fundamentó en la técnica de bola de nieve, consistente en plantear unos contactos iniciales ya sea con personas susceptibles de ser entrevistadas o no, que nos facilitaban los datos de otras personas que a su vez eran contactadas, procediendo así sucesivamente.

En total se entrevistaron 23 personas. Un criterio en el desarrollo de las entrevistas era tratar de mantener cierta paridad entre hombres y mujeres. Esto se logró en cierta medida con 13 entrevistas a mujeres y 10 a hombres. Las personas entrevistadas tenían diversos orígenes regionales y sociales, y estudiaban en diferentes universidades de Bogotá.

Las entrevistas fueron transcritas en su totalidad a formato escrito en medio magnético. En términos generales, nos apoyamos en una herramienta de análisis cualitativo asistido por computador para analizar e interpretar los relatos, se utilizó el software Nvivo (Valles, 2000). El proceso de categorización y análisis de las entrevistas se basó, 
en parte, en algunos de los aprendizajes de la teoría fundamentada ${ }^{6}$. Sin embargo, no quisiéramos inscribir nuestra metodología de análisis como una investigación con base en teoría fundamentada pues en términos generales no se siguieron al pie de la letra los procedimientos establecidos por la misma.

Nuestra metodología de categorización y análisis de las entrevistas se ubicó entonces desde una perspectiva netamente inductiva, de corte cualitativo en donde lo importante de los análisis fue la coherencia y la transparencia en vez de la representatividad y la validez. A partir de esta forma de leer los datos la idea era tratar de olvidar la teoría y comenzar a generar categorias de análisis a partir de los datos en sí mismos, como cuando uno está estudiando un texto completamente desconocido. A partir de esas primeras categorías de análisis se comenzaron a identificar relaciones entre ellas, lo cual iba generando categorias más abstractas y así sucesivamente. Los resultados de este proceso de categorización y de análisis se desarrollan a continuación, en especial con la presentación de los principales mecanismos de racismo cotidiano identificados en las universidades a través de los relatos orales de los estudiantes entrevistados.

\section{La constante y sutil alterización subordinada de los estudiantes negros en las universidades bogotanas}

Desde el punto de vista metodológico, se analizaron los mecanismos mediante los cuales se expresa el racismo en la vida cotidiana de los estudiantes con la identificación de la complicación en los relatos orales. Esta categoria de análisis, que también se deriva de las teorias lingüísticas de la narración y ha sido puesta a prueba en los estudios pioneros sobre el racismo cotidiano (Van Dijk, 2010), es similar a la de nudo en la estructura narrativa literaria. Tiene la facultad de organizar la información sobre los eventos y las acciones que son interpretados como disruptivos o desviados en comparación con lo considerado como normal en una situación. Se trata entonces de una descripción e interpretación de las acciones frente a las normas y valores que se tienen sobre una conducta aceptable o no aceptable.

6 La teoría fundamentada se puede definir como "una metodología general de análisis relacionada con la colección de datos, que usa un conjunto de métodos sistemáticamente aplicados para generar una teoria inductiva sobre un área substantiva. El producto de la investigación constituye una formulación teórica o un conjunto integrado de hipótesis conceptuales sobre el área substantiva de estudio" (Glaser, 1992, pp. 16) (la traducción es nuestra). 
En ese sentido, para el total de 23 entrevistas analizadas hemos identificado un total de 43 mecanismos distintos, los cuales fueron codificados en un total de 345 referencias $^{7}$. Aunque en este escrito no podemos desarrollar todos de manera sistemática, presentaremos algunos mecanismos del racismo cotidiano que nos parecen significativos desde el punto de vista sociológico y a partir de los cuales se entiende nuestra principal conclusión en relación con la constante y sutil (o eufemística) alterización subordinada que estos estudiantes deben enfrentar en su cotidianidad universitaria.

\section{Algunos mecanismos del racismo cotidiano encontrados en las universidades}

Mientras hacíamos el trabajo de campo en algunas universidades de Bogotá, tuvimos la oportunidad de hacer observaciones participantes tanto en los campus como en algunos salones de clase. En una ocasión nos pudimos colar ${ }^{8}$ a una clase de derecho civil en una universidad privada en la jornada nocturna, por intermedio de una amiga afrocolombiana que estudiaba allí. Se trataba de un grupo de más o menos treinta estudiantes, muchos de ellos trabajadores de tiempo completo. Se deduce que la mayoría trabajaban como empleados de oficinas pues vestian trajes o vestidos formales. En ese grupo había, además de nuestra amiga, dos estudiantes afrocolombianos, una mujer, a quien después entrevistariamos y un hombre de aproximadamente 21 años de edad. La metodología de la clase ese día consistía en un examen parcial, en donde los estudiantes se reunian en parejas y contestaban de forma escrita a unas preguntas que la profesora había preparado con anticipación.

En el proceso de conformación de los grupos, que es algo informal según los intereses y empatías de los estudiantes, el estudiante negro se quedó solo, mientras la mayoría de estudiantes ya habian formado parejas. Uno de sus compañeros se percató de la situación y en voz alta, dirigiéndose al estudiante pero cerciorándose que todos lo escucharan, dijo: "Oiga hermano, ¿por qué está solo?[...] desde que ganó Obama[...] ¡quién sabe este tipo qué se está creyendo!". Ante el comentario hubo

\footnotetext{
Una referencia equivale a un fragmento o conjunto de fragmentos de una entrevista en el cual se relata una situación que puede ser considerada como racista o discriminante por parte de la persona entrevistada.

8 Queremos decir aquí que logramos entrar a la clase haciéndonos pasar como estudiantes y en donde nuestros propósitos de investigación no fueron evidentes para el conjunto de las personas co-presentes en el salón de clase.
} 
una reacción de risas esporádicas por parte de algunos de los compañeros del grupo. El estudiante no tuvo ninguna reacción en particular, su actitud fue casi ignorar el comentario de su compañero mientras lograba hacer pareja con otro compañero que había acabado de ingresar al salón de clases.

Inmediatamente después de que el compañero hubiera mentado el chascarrillo sobre Obama, la profesora se percató de lo incómodo que habia podido ser ese comentario para el estudiante afrocolombiano, entonces se acercó a él y le dijo, en un tono algo compasivo y en búsqueda de empatía: "sí, es que el negro está de moda, ¿cierto?". El estudiante sólo dirigió su mirada hacia ella con una expresión seria y la profesora balbuceó una que otra palabra, como tratando de explicarse a sí misma, pero sin mucho éxito. Finalmente, con una sonrisa que denotaba algo de vergüenza, siguió caminando y se dirigió al fondo del salón, a la espera que todos los estudiantes conformaran parejas para poder iniciar el examen.

En este ejemplo se pueden apreciar por los menos cinco mecanismos del racismo cotidiano identificados en los resultados de esta investigación. El primero tiene que ver con el aislamiento-grupismo el cual ha sido relatado por los estudiantes entrevistados como uno de los más experimentados en la universidad. Como su nombre lo indica, este consiste en que los estudiantes se ven aislados constantemente, muy pocas personas les hablan e incluso les niegan ayudas básicas de una supuesta solidaridad estudiantil. Muchas veces este aislamiento genera un mecanismo ligado que tiene que ver con la búsqueda de refugio en otras personas iguales, como otros estudiantes negros u otros estudiantes racializados, como los costeños, lo que hace que se generen grupos en el seno del salón de clases o del campus universitario.

Un segundo mecanismo que se puede apreciar en el anterior ejemplo es el de la reactualización del racismo con base en referentes sociales o culturales, el cual se hace evidente con la referencia al presidente de los Estados Unidos, Barack Obama. Desde luego, es una referencia coyuntural pues esta situación ocurrió unos meses después de la elección del presidente norteamericano pero demuestra cómo puede ser de flexible la reproducción del racismo en una sociedad como la colombiana.

Más allá de esa reactualización también está implícito un mensaje según el cual el estudiante afrocolombiano es quien tiene un problema por el hecho de no haber encontrado pareja para responder el parcial. Esto obedece a la problematización, otro de los mecanismos 
más frecuentes en el contexto universitario. Consiste en endilgar el problema o la culpabilidad de la situación a las personas racializadas. Es una forma de estigmatización que se reduce al esquema mental: "los negros sí que son problemáticos"; esto también ocurre en ocasiones cuando las personas racializadas ejercen activamente sus derechos y manifiestan su inconformidad en determinado tipo de situaciones. Además, cuando el estudiante dice "este tipo qué se está creyendo" está intimidando pues hay un referente claro a las relaciones de poder entre los negros y nosotros. El mensaje es bastante tosco pero demuestra la lógica de un pensamiento prejuiciado: "si ganó Obama, que es 'negro', entonces este 'tipo' puede tomarse atribuciones que no le competen, por eso es necesario hacerle una advertencia". A pesar de que estas advertencias no necesariamente tengan consecuencias objetivas, sí tienen un poder simbólico importante pues su propósito es tratar de mantener el status quo, es decir la dominación y las distinciones sociales, frente a una posible amenaza, ya sea esta real o imaginada.

Por último, entraría un mecanismo que tiene que ver con la reacción de la profesora al comentario del estudiante. Cabe anotar que la consideramos una reacción pues en la actitud de ella estaba claro que el comentario había sido inapropiado para la situación; sin embargo, y a pesar de las buenas intenciones, su comentario no hizo sino reforzar el hecho de que el estudiante en particular habia sido puesto en el centro de la atención sin que hubiera hecho nada para merecérselo, simplemente por el hecho de ser negro. Así pues, su actitud es un ejemplo del mecanismo del paternalismo y la condescendencia. Con base en este paternalismo se acercó al estudiante racializado para expresar su empatía, la cual era artificial de acuerdo con las circunstancias. Tampoco sopesó sus palabras y de forma indirecta, encasilló al estudiante como negro, así hubiera querido darle una connotación positiva al decir que "estaba de moda". La reacción posterior del estudiante y la vergüenza que ella expresó confirmaron lo inapropiado de su comentario pues en cierta forma reforzó, mas no contuvo el racismo expresado en el primer comentario del otro estudiante.

\section{El carácter eufemistico del racismo en las universidades}

Es posible ver cómo en una simple situación de interacción social, cara a cara en este caso, el equilibrio en el ritual de la interacción (Goffmann, 1970) se pierde en la medida en que hay acciones y palabras de varios de los actores sociales que no son acordes con lo que se espera de la situación. 
Pero estas acciones y palabras estaban mediadas por prejuicios en torno a la raza negra, de los cuales se convirtió en objetivo el estudiante así racializado. Por otro lado, es menester recordar aquí que no se trata de un análisis de la problemática social del racismo desde una perspectiva de la lógica del juicio (Wacquant, 1997). De hecho, como lo acabamos de ver puede que las acciones de la profesora hubieran sido motivadas por las más buenas intenciones, pero aún así estas coadyuvaron a reforzar el carácter racista de la situación.

De igual forma puede ocurrir con el estudiante o los estudiantes que constantemente ejercen acciones y actitudes racistas que afectan a personas racializadas. Puede que para ellos estas situaciones sean completamente normales, pues hacen parte de la configuración de las relaciones de poder y de las jerarquias sociales de las cuales, de manera directa o indirecta, se han beneficiado. En ese sentido, puede que el estudiante en cuestión no entienda las consecuencias racistas de sus actos; incluso cuando se le informa de tales consecuencias una y otra vez. Sin embargo, esta falta de consciencia o, más bien, de negación de la problemática no excusa para nada sus acciones, sino que constituye otro mecanismo de manifestación del racismo cotidiano; como se ha identificado en algunos estudios bajo la expresión típica de "yo no soy racista pero..."(Bonilla Silva, 2006).

En ese sentido, la situación anterior está lejos de ser un caso aislado, otro recurso de auto-justificación del racismo, sino que hace parte de todo un cúmulo de situaciones similares, ejercidas por el mismo estudiante, o por otros racialmente dominantes, contra los estudiantes negros del salón. De esa forma nos lo comenta Sofia, la otra estudiante afrocolombiana que estaba presente y a quien entrevistamos unos días después:

-[...] ¿y qué otro tipo de situaciones ha habido en la universidad?

-En reuniones también, de pronto con gente diferente a amigos y compañeros también. La gente hace como muchos chistes, aquí en Colombia la gente todavía no supera eso, el hecho de que hayan negros... sí, esos chistes todos...

$-¿ ¿$ Y tú cómo reaccionas en esa situación de reuniones o...? 
-No, yo muchas veces me quedo callada, no digo nada, trato de no ponerme de mal genio porque... pero a mis compañeros cuando de pronto... Hubo un compañero una vez que dijo algo y yo le pedí el favor, "mira Carlos, te pido el favor, no hagas esos comentarios, por lo menos del color y eso delante de mí porque me disgusta". - "No pero nena, yo no lo digo por ti, porque tú no eres negra"... Le dije "no interesa, no me gusta... ¡mi familia es negra!”, le dije yo así. Entonces ya respeta mucho eso, ya por ejemplo Carlos no [...]

La situación relatada por la estudiante nos da más luces sobre el carácter repetitivo de este tipo de situaciones racistas en la universidad. Si bien ella comienza hablando sobre los chistes y las bromas como algo que se ejerce constantemente sobre los estudiantes negros, termina por recordar y mencionar una situación parecida en la cual el mismo estudiante siguió siendo el objetivo de la broma sobre Obama. Sin embargo, hay unas configuraciones del micro poder en el salón de clase que es necesario retomar. Sofia también fue objeto de los chistes y las bromas pero su actitud, luego de sobrellevarlo por varios semestres, fue la de reaccionar de forma asertiva para que sus compañeros no la siguieran molestando. La reacción por parte del agente del racismo fue la de excusar su chiste diciendo que este no estaba dirigido a ella porque él no la consideraba negra. Esto obedece al mecanismo de Considerar una persona 'negra' como la buena excepción; es decir, como la excepción al estigma negativo que ha sido generalizado socialmente y recae en todas las personas que son socialmente consideradas como negras. En ese sentido, a pesar de que la racialización quede implícita, hay un esfuerzo forzado por parte del agente del racismo de tratar de negar una identificación racializada para evitar que la persona racializada caiga en el estigma de los negros, pero que lo único que logra es justamente reforzar la estigmatización racial.

Por otro lado, la reacción de Sofia generó eficazmente que sus compañeros cesaran los chistes y las bromas contra ella, pero no contra otros estudiantes negros del salón; en este caso el joven que ha sido objeto de la broma sobre Obama. Puede observarse además que él tiene la condición de ser uno de los más jóvenes del grupo, además de que proviene de otro grupo, es decir, el nuevo, el más joven y el más negro. Los reclamos de Sofia no son entonces eficaces a la hora de controlar el racismo cotidiano ejercido por sus compañeros pues estos encontraron un objetivo mucho más vulnerable según las configuraciones sociales del micro poder en el salón de clases. Además de que el estudiante afectado no tiene la misma reacción que Sofia sino más bien opta por dejar 
pasar las situaciones sin expresar su desacuerdo a sus compañeros. $\mathrm{Ni}$ siquiera cuando Sofia sale en su defensa esto sirve para que la práctica racista cese. Aquí también podemos considerar la situación como una forma de mantener a raya al estudiante racializado.

Por un lado, es nuevo y joven, lo cual puede ser visto por sus compañeros como algo amenazante en el propósito de mantener las jerarquias intragrupales. Por otro lado es hombre y esto significa además una posible amenaza para el dominio masculino en el salón de clases, máxime si se tienen en cuenta todos los mitos relacionados con las dotes sexuales extraordinarias de los hombres negros (que obedece al mecanismo de exotización sexual). No en vano, recordémoslo, el trasfondo de la broma sobre Obama es "este tipo la quiere montar", o “¿qué se está creyendo?”; expresiones muy colombianas para referirse a las relaciones de poder y las jerarquías entre las personas.

Otro de los mecanismos con mayor frecuencia en el relato de los estudiantes consiste en manifestar una mayor severidad en la aplicación de las reglas. Se basa en un trato diferenciado que puede influir negativamente en el desempeño académico de los estudiantes en la medida en que son tratados con mayor dureza principalmente por sus profesores. La forma más frecuente por medio de la cual esto se expresa en la vida cotidiana universitaria obedece a actitudes de inflexibilidad en la calificación; por tal motivo, esto puede generar sentimientos de inseguridad y de persecución en los estudiantes así tratados, a tal punto que algunos de ellos sienten estar al límite de la paranoia. La dedicación en los estudios no parece entonces ser garantía para obtener mejores resultados académicos; frases como "él siempre me rajaba" ilustran esta experiencia, la cual es percibida como injusta y es el reflejo de la condición subordinada de los estudiantes racializados en el seno del sistema educativo:

Yo una vez tuve un problema con el profesor, porque el profesor me discriminó así directamente en términos de que no me quiso aceptar un trabajo que yo había hecho, eh que lo escribí a mano y que eso era normal en esa época porque la gente todavía no estaba muy familiarizada con los computadores y esto... era mi profesor de radio, me acuerdo tanto, hice las entrevistas y dijo -"mejor organicemos una cola", como una fila con todos los compañeros y cada uno iba entregando su trabajo, entonces yo le entregué el mío, eh la persona que iba antes de mí no le entregó nada, que no, le salió con cincuenta mil excusas y el profesor realmente no sé qué fue lo que le dijo, bueno se fue; seguí yo y yo que sí le llevé mi material, mi casete 
de la entrevista, mi trabajo, tenía que hacer una crónica, la historia de vida pero desarrollado en formato de crónica, había hecho la historia de vida y la trascripción de la entrevista, lo único que me faltaba era hacer el... eh escribir, escribir la crónica ¿ ¿í?, para grabarla, eh... porque uno hace como el recuento de... de, de la historia de vida y luego hace el formato literario, la crónica es como muy literaria ¿no?, entonces el tipo me dijo que no, que "cómo yo le llevaba un trabajo así, en esa condición, mire esa hoja, es que eso escrito a lapicero", que no sé qué, no sé cuando, yo le dije "vea, y el tipo que pasó antes de mí usted porqué no le dijo nada",- "no, es que al menos... al menos él no me trajo una cosa de estas". Mary.

La calificación se convierte así en el principal recurso de intercambio en la interacción profesores-estudiantes, por tal motivo es una fuente de conflicto entre ellos. Aunque tiene la apariencia de ser objetiva, pues se fundamenta en el espejismo de la cifra, la calificación es el punto de encuentro entre las expectativas subjetivas de uno y otro actor social en la relación educativa. Como se dijo más atrás, está relación no es sin embargo, horizontal sino que está mediada por una relación de poder que le da la ventaja al profesor sobre el alumno; por tal motivo, los estudiantes racializados pueden desarrollar estrategias basadas en un seguimiento cercano a la forma en que califica el profesor y en donde la menor indicación de tratamiento desigual es identificada casi de manera inmediata (ver relato anterior). Este es también un aspecto que puede generar celos y hasta competencia desleal entre los estudiantes pues, recordémoslo, un buen desempeño académico por parte de los estudiantes racializados es percibido más bien como la excepción a la regla.

La mayor severidad en la aplicación de las reglas puede significar la reproducción de determinadas desigualdades sociales y educativas, como se apreció en el relato de Mary en donde su profesor no le aceptó el trabajo pues este estaba escrito a mano y no en computador, como es costumbre en esos casos. El sentimiento de injusticia por el trato desigual se vio confirmado por el hecho de que uno de sus compañeros ni siquiera entregó el trabajo, para lo cual el profesor no se mostró tan severo. En este caso específico se combinarian el mecanismo de mayor severidad en la aplicación de las reglas con el mecanismo del trato privilegiado a otras personas. Los anteriores relatos nos recuerdan una vez más el carácter sutil o eufemístico del racismo cotidiano en el contexto universitario, en donde se puede argumentar que no se trata de una situación discriminatoria sino que la responsabilidad 
recae en el estudiante. En esta sutilidad del racismo se fundamenta entonces su función inercial y repetitiva en el mantenimiento de las relaciones de dominación social en el campo universitario.

\section{A manera de conclusión. La necesidad social de visibilizar las discriminaciones en la universidad}

En la época en la que se escribe este artículo, se da la coincidencia de que aparece publicado un artículo sobre las discriminaciones raciales en la universidad colombiana en un periódico de divulgación nacional $^{9}$. El artículo relata cómo una pareja de hermanos afrocolombianos interpusieron tutela a su universidad por haber recibido trato discriminatorio "por su color de piel". El artículo anuncia que luego de esta demanda, el pasado 31 de mayo de 2013 el rector de la universidad ofreció disculpas públicamente a los estudiantes demandantes, para lo cual el estudiante afirma que no es suficiente y que lo importante es que la gente denuncie el racismo ante las autoridades y no tenga miedo a las represalias.

Esta noticia es paradójicamente alentadora puesto que por un lado demuestra que se está comenzando a visibilizar el tema del racismo en las universidades en Colombia, pero por otro lado, refleja también el carácter sutil y repetitivo del racismo cotidiano que identificamos mediante nuestra investigación y que no necesariamente se hace evidente por medio de protestas o incluso de denuncias a nivel penal y jurídico.

Se aprecia así la necesidad social de visibilizar discriminaciones en un campo social que histórica e ideológicamente se ha construido en valores de universalidad y de meritocracia que, en principio, no dan lugar a discriminación de ninguna índole. Nuestro aporte desde la investigación sociológica ha sido entonces el tratar de desmitificar este ethos universalista de la universidad, mostrando que de hecho hay una constante racialización de las relaciones sociales en su cotidianidad, la cual tiende a reproducir la tendencia a encasillar como inferiores a los estudiantes negros y por consiguiente reproduce las desigualdades sociales y educativas como elemento

9 Se trata del artículo "El hombre que logró que su universidad le pidiera perdón por racismo". El Tiempo. Junio 16 de 2013. Disponible en línea: http://www.eltiempo.com/colombia/bogota/lahistoria-de-heiler-yesid-ledezma-quien-sufrio-de-racismo-en-universidad-de-bogota_12875171-4. Última revisión, 22/07/2013. 
central en la permanencia de la dominación socio-racial que tiene sus raíces en la historia colonial del país.

Visibilizar las discriminaciones raciales en la universidad, ya sea desde las comunidades afectadas o desde la investigación en ciencias sociales, tiene su importancia social en la medida en que permite dar herramientas para entender el racismo como un fenómeno social contemporáneo y poder vislumbrar alternativas y estrategias para hacer frente a dicho fenómeno. Al respecto, es importante mencionar lo ocurrido en Estados Unidos, en donde luego de la desegregación de las escuelas y de las universidades se desarrolló una importante acción pública a partir de la puesta en marcha de las acciones afirmativas pero que, como lo demuestran algunos analistas estadounidenses (Feagin y Barnett, 2004), se vieron afectadas por la reproducción y el mantenimiento del racismo en las universidades e instituciones educativas.

El caso estadounidense constituye un duro aprendizaje del cual deberian tomar nota las universidades colombianas y quienes definen la politica educativa y se muestran interesados en disminuir las desigualdades sociales que afectan a las minorias étnicas en Colombia; así como la sociedad colombiana en conjunto que parece seguir una tendencia latinoamericana a ignorar la existencia de las discriminaciones y mucho más cuando se trata del campo educativo, en general, y de la educación superior en particular. El presente artículo propuso dar herramientas para minimizar esta invisibilización. 


\section{Referencias}

Agudelo, C. E. (2002). Poblaciones negras y politica en el pacifico colombiano: las paradojas de una inclusión ambigua. Tesis de doctorado en Sociología (versión en Español) no publicada. Instituto de Altos Estudios de América Latina Universidad La Sorbonne Nouvelle - Paris III. Paris, Francia.

Arocha, J., Guevara, N., Londoño, S., Moreno, L. y Rincón,L. (2007, agosto). Elegguá y respeto por los afrocolombianos: una experiencia con docentes de Bogotá en torno a la Cátedra de Estudios Afrocolombianos. Revista de Estudios Sociales. Dossier Raza y Nación (II), (27), 94-105.

Bonilla-Silva, E. (2006). Racism without racists. Maryland: Rowman y Littlefield Publishing.

Bonilla-Silva, E. (2011). ¿Qué es el racismo? Hacia una interpretación estructural. En Mosquera Rosero-Labbé, C., Laó-Montes, A. y Rodríguez Garavito (Eds.). Debates sobre ciudadania y politicas raciales en las Américas Negras (pp. 649-698). Bogotá: Universidad Nacional de Colombia. Facultad de Ciencias Humanas. Centro de Estudios Sociales-CES/ Universidad del Valle.

Caicedo, J. A. y Castillo, E. (2008). Indígenas y afrodescendientes en la universidad colombiana: Nuevos sujetos, viejas estructuras. Cuadernos Interculturales, primer semestre, 6 (10), 62-90.

De Rudder, V., Poiret, C. y Vourc'h, F. (2000). L'inégalité raciste. L'universalité républicaine à l'épreuve.Paris: Presses Universitaires de France.

Essed, P. (1990). Everyday Racism. Reports from Women of two Cultures. Claremont: Hunter House.

Essed, P. (1991). Understanding Everyday Racism. An Interdisciplinary Theory. Newbury Park, California: Sage Publications.

Feagin, J. y Barnett, B. (2004). Success and Failure: How Systemic Racism Trumped the Brown vs. Board of Education Decision. Illinois Law Review, (5), 1099-1130.

Fonseca, C. I. (2009). Aproximaciones teóricas y metodológicas a los estudios del racismo. Documento de Trabajo No. 6 / Document de Travail No. 6, Colombia: Proyecto AFRODESC.

Gaviria, A. (2002). Los que suben y los que bajan. Educación y movilidad social en Colombia. Bogotá: Fedesarrollo-Alfaomega.

Gil, F. (2010). Vivir en un mundo de 'blancos'. Experiencias, reflexiones y representaciones de 'raza' y clase de personas negras de sectores medios en Bogotá D.C. Tesis de Magíster en Antropología no publicada. Universidad Nacional de Colombia. Bogotá, Colombia.

Glaser, B. (1992). Theoretical sensitivity. Advances in the methodology of Grounded Theory. Mill Valley, California: Sociology Press. 
Goffman, E. (1970). Ritual de la interacción. Buenos Aires: Tiempo contemporáneo.

Guillaumin, C. (1992/2010).Una sociedad en orden. Sobre algunas de las formas de la ideología racista. En O. Hoffmann y O. Quintero (Coords.). Estudiar el racismo. Textos y herramientas (pp. 36-52). Documento de Trabajo No. 8 / Document de Travail No. 8, México: Proyecto AFRODESC / EURESCL.

Langebaek, C. y Leal, C. (2007, agosto). Presentación. Revista de Estudios Sociales. Dossier Raza y Nación (II), (27), 11-13.

Meertens, D. (2008, julio-diciembre). Discriminación racial, desplazamiento y género en las sentencias de la Corte Constitucional. El racismo cotidiano en el banquillo. Universitas Humanistica, (66), 83-106.

Meertens, D., Viveros, M. y Arango, L. G. (2006). Discriminación étnico-racial, desplazamiento y género en los procesos identitarios de la población negra en sectores populares de Bogotá. Clacso-Crop, Cidse.

Meza, L. G. (2008). Reproducción de las desigualdades sociales y raciales en la UN: Los afrocolombianos. Trabajo de Grado de Sociología no publicado. Universidad Nacional de Colombia. Bogotá, Colombia.

Mosquera, C. (2007, agosto). Lecturas criticas de los talleres de salud sexual y reproductiva y de fortalecimiento cultural desarrollados con mujeres negras desterradas por el conflicto armado en Colombia. Revista de Estudios Sociales. Dossier Raza y Nación (II), (27), 106-121.

Palacios, L. (2005). Caracterización fenotípica, diferenciales y desigualdades en la Universidad del Valle. Trabajo de grado de Sociología no publicado. Universidad del Valle. Cali, Colombia.

Poiret, C. y Vourc'h, F. (1998). Reperer les discriminations Ethniques et raciales dans le domaine du travail et de l'emploi. Paris: Unité de Recherche Migrations et Societé (URMIS) CNRS/Université Paris 7-Denis Diderot.

Poutignat, P. y Streiff-Fenart, J. (1995). Théories de l'ethnicité. Paris: Presses Universitaires de France.

Quintero, O. (2013). Racisme et Discrimination à l'université. Lectures croisées des sociétés Française et Colombienne à partir de l'expérience vécue des étudiants noirs à Paris et Bogota. Tesis de Doctorado en sociologia no publicada. Université Rennes.Rennes, Francia. Versión en español recuperada dehttp:// tel.archivesouvertes.fr/tel-00807356

Urrea, F. (2011, abril). La conformación paulatina de clases medias negras en Cali y Bogotá a lo largo del siglo XX y la primera década del XXI. Revista de Estudios Sociales, (39), 24-41.

Valles, M. (2000). La grounded theory y el análisis cualitativo asistido por ordenador. En M. García, J. Ibáñez y F. Alvira: El análisis de la realidad social (pp. 577-603). Madrid: Alianza (3 ${ }^{a}$ edición). 
Van Dijk, T. A. (2010). Discurso y racismo. En O. Hoffmann y O. Quintero (Coord.). Estudiar el racismo. Textos y herramientas (pp. 102-128). Documento de Trabajo No. 8 / Document de Travail No. 8, México: Proyecto AFRODESC / EURESCL,.

Viáfara, C.A. y Urrea, F. (2006). Efectos de la raza y el género en el logro educativo y estatus socio-ocupacional para tres ciudades colombianas. Desarrollo y Sociedad, 115-163.

Viveros, M. (2007, agosto). Discriminación racial, intervención social y subjetividad. Reflexiones a partir de un estudio de caso en Bogotá. Revista de Estudios Sociales. Dossier Raza y Nación (II), (27), 106-121.

Wacquant, L. (1997). For an Analytic of Racial Domination. Political Power and Social Theory, 11, 221-234.

Wade, P. (1997). Gente negra, Nación mestiza. Dinámicas de las identidades raciales en Colombia. Bogotá: Ediciones Uniandes. 